\title{
Endoplasmic Reticulum Stress-Associated Chaperones, Bip/ GRP78 and Calnexin are Overexpressed in Keratocystic Odontogenic Tumours
}

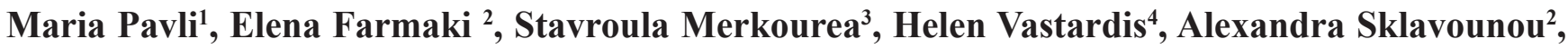 \\ Fotios Tzerbos ${ }^{1}$, Ioulia Chatzistamou ${ }^{4}$
}

${ }^{1}$ Clinic of Oral and Maxillofacial Surgery, Dental School, National and Kapodistrian University of Athens, Greece. 2Department of Biochemistry, Medical School, National and Kapodistrian University of Athens, Greece.

${ }^{3}$ Department of Oral Medicine and Pathology, Dental School, National and Kapodistrian University of Athens, Greece.

${ }^{4}$ Department of Basic Sciences, Dental School, National and Kapodistrian University of Athens, Greece.

\author{
Corresponding Author: \\ Ioulia Chatzistamou \\ Department of Basic Sciences, Dental School \\ National and Kapodistrian University of Athens \\ Thivon 2, 11527, Athens \\ Greece \\ E-mail: chatzist@dent.uoa.gr \\ Phone: $+30-210-7461222$ \\ Fax: $+30-210-7461220$
}

\begin{abstract}
Objectives: Odontogenic keratocysts (OKCs) are developmental cysts that have been reclassified according World Health Organization (WHO), to keratocystic odontogenic tumours (KCOTs), a term that better reflects their neoplastic nature. The aim of present study is to evaluate the induction of stress of the endoplasmic reticulum and execution of the resulting unfolded protein response in keratinocystic odontogenic tumours.

Material and Methods: We analyzed by immunohistochemistry the expression of the chaperones BiP/GRP78 and calnexin in 24 cases of KCOTs. As controls, we have used 9 cases of periapical or radicular cysts (PACs) and 5 cases of Fibromas (FBs). The PACs and the FBs were included in the analysis, as PACs are the most common type of inflammatory odontogenic cysts of and FBs, as lesions of the connective tissue with unaffected epithelium.

Results: Analysis revealed a strong association between both BiP/GRP78 and calnexin expression and KCOTs: 18 out of 24 (75\%) KCOTs expressed BiP/GRP78 as opposed to 1 out of 9 (13\%) PACs, and none of 5 FBs evaluated (P $<0.001, \mathrm{x}^{2}$-test). Calnexin was expressed in 11 out of 24 KCOTs (46\%) but only one out of 9 (13\%) PACs, and none of the 5 FBs analyzed $\left(\mathrm{P}<0.001, \mathrm{x}^{2}\right.$-test $)$.

Conclusions: Study results imply that induction of endoplasmic reticulum stress maybe of diagnostic value in keratocystic odontogenic tumours characterization. In addition to recent findings suggesting that endoplasmic reticulum stress plays a causative role in keratinization of epithelia, pharmacological interference with the execution of the unfolded protein response should be considered for the management of keratocystic odontogenic tumours.
\end{abstract}

Keywords: dental tissue neoplasms; endoplasmic reticulum stress; GRP78 protein; molecular chaperone; phosphoprotein pp90.

Accepted for publication: 28 March 2014

To cite this article:

Pavli M, Farmaki E, Merkourea S, Vastardis H, Sklavounou A, Tzerbos F, Chatzistamou I. Endoplasmic Reticulum StressAssociated Chaperones, Bip/GRP78 and Calnexin are Overexpressed in Keratocystic Odontogenic Tumours.

URL: http://www.ejomr.org/JOMR/archives/2014/1/e3/v5n1e3ht.pdf

doi: $10.5037 /$ jomr.2014.5103 


\section{INTRODUCTION}

The formation of cysts in the jaws possesses unique features regarding their pathology and implicates the odontogenic tooth-forming apparatus [1]. In most classification schemes odontogenic cysts are divided in two major categories, namely the developmental cysts and the cysts that are initiated in areas of acute or chronic inflammation, with odontogenic keratocysts $(\mathrm{OKC})$ and periapical or radicular cysts (PACs) as the most common types, respectively [ $[1, \underline{2}]$. The World Health Organization (WHO) reclassified OKC in its 2005 edition of histological classification of odontogenic tumours and according to this reclassification, the $\mathrm{OKC}$ is now considered as a KCOT. It is defined as "a benign uni- or multicystic, intraosseous tumour of odontogenic origin, with a characteristic lining of parakeratinized stratified squamous epithelium that bears the potential for aggressive, infiltrative behaviour", a term that better reflects its neoplastic nature [3]. Several factors form the basis of this decision: a. the clinical behaviour of the lesion, since KCOT is locally destructive and highly recurrent, b. the histopathologic characteristics, considering that the basal layer of the KCOT budding into connective tissue, in addition to the mitotic figures that are frequently found in the suprabasal layers $[\underline{1}, \underline{3-5}]$, and finally c. genetic alterations, are the most important parameters [6]. KCOTs comprise approximately $11 \%$ of all cysts of the jaws [7]. They occur most commonly in the mandible, especially in the posterior body and ramus regions $[1,2,7]$. It may be solitary or multiple and the latter is usually characterizing the inherited nevoid basal cell carcinoma syndrome "NBCCS". KCOTs have a high recurrence rate, ranging between $25 \%$ and $60 \%$ while when associated with nevoid basal cell carcinoma syndrome "NBCCS" or Gorlin-Goltz syndrome, the recurrence rate is about $82 \%[\underline{8}, \underline{9}]$. So far, there is only limited evidence regarding the pathogenesis of the developmental cystic neoplasms of the jaws and for this reason they are considering of unknown aetiology. The endoplasmic reticulum (ER) is an organelle with a major role in the synthesis of lipid and proteins and leads many cellular processes such as organogenesis, transcriptional activity, stress responses, and apoptosis [10-14]. ER is responsible for the proper folding of the newly synthesized proteins that is facilitated with the assistance of various ER chaperones $[\underline{10}, \underline{11}]$. Unfolded or malfolded proteins are disposed by mechanisms implicating ER-associated protein degradation (ERAD). When the amount of unfolded protein exceeds the folding capacity of the ER, human cells activate a homeostatic defence mechanism designated as the UPR that follows ER stress [11-16].

Among the various consequences of UPR is also the upregulation of $\mathrm{BiP} / \mathrm{GRP} 78$ and of other chaperones that is considered diagnostic for the induction of ER stress in a given tissue [16-18]. BiP/GRP78 binds to the hydrophobic region of unfolded proteins via a substrate-binding domain and facilitates folding through conformational change evoked by the hydrolysis of ATP by the ATPase domain $[\underline{19}, \underline{20}]$.

Calnexin and calreticulin are ER chaperones specifically involved in the folding of glycoproteins. High mannose type oligosaccharide is attached en bloc to most proteins synthesized in the ER, and then trimmed sequentially [21-23]. When two glucose residues are trimmed by glucosidase I or II and the protein contains only one glucose residue, calnexin and calreticulin bind and fold the client protein $[21,22]$. When the last glucose residue is trimmed by glucosidase II, the client is released from calnexin and calreticulin, and binds to UDPglucose-glycoprotein glucosyltransferase $[\underline{10}, \underline{21}]$. If the protein is folded properly, it is released from the enzyme and transported to the Golgi apparatus. If it is not folded appropriately, UDP-glucose-glycoprotein glucosyltransferase attaches one glucose residue and returns it to calnexin and calreticulin. This folding process is called the calnexin cycle. Calnexin and calreticulin share a similar molecular structure and function, although they are transmembrane and luminal proteins, respectively $[\underline{10}, \underline{11}, 21,22]$.

Considering the neoplastic nature of KCOTs, in combination with their poorly defined aetiology we explored if ER stress is involved in disease development. Specifically, we evaluated the expression of the chaperones, BiP/GRP78 and calnexin in a panel of KCOTs as compared to PACs and FBs. Both of these markers is considered to accurately reflect the induction of ER stress which has been associated with neoplastic development $[\underline{10}, \underline{11}]$.

\section{MATERIAL AND METHODS Patients and samples}

Paraffin-embedded tissue specimens of KCOTs (24 cases), PACs (9 cases) and Fibromas (5 cases) were randomly selected from the archives of the Department of Oral Pathology, of the National and Kapodistrian University of Athens, Dental School spanning the years 2006 - 2011 and were analyzed by immunohistochemistry. We have analyzed the expression of chaperones BiP/GRP78 and calnexin 
in a panel of 24 KCOTs and 9 PACs. The latter represent the most common type of inflammatory odontogenic cysts. In addition we have also included in our analysis 5 FBs as controls since they represent lesions of the connective tissue devoid of pathological findings in the epithelium.

\section{Details of ethics approval}

No ethical issues are related to this study since only paraffin-embedded archival material has been used and no data related to the patients' clinical records have been disclosed. Therefore the study did not require review by the Institutional Review Board of the University of Athens.

\section{Immunohistochemistry}

Immunohistochemistry was carried out in formalin fixed, paraffin embedded tissue specimens. The antibodies used were monoclonal rabbit anti-BiP (C50B12), by Cell Signaling Technology; 1:100 and monoclonal mouse anti-calnexin (sc-46669), by Santa Cruiz Biotechnology, Santa Cruz, CA, USA; 1:75. Immunostaining was performed by using the Superpicture Polymer (Dab) Kit (Novocastra), following the manufacturer's instructions. Before evaluation, a weak counterstaining with hematoxylin was performed in all immunostained specimens. Specimens were evaluated blindly from two authors of the study (I.C., Pathologist and S.M., MSc in Oral Medicine and Pathology). The positive immunohistochemical staining, was graded semiquantitatively by using a 5-tier scoring system and classified according to the intensity of the labelling as: negative $(-)$, marginal $(+/-)$, mild $(+)$, moderate $(++)$ and intense $(+++)$.

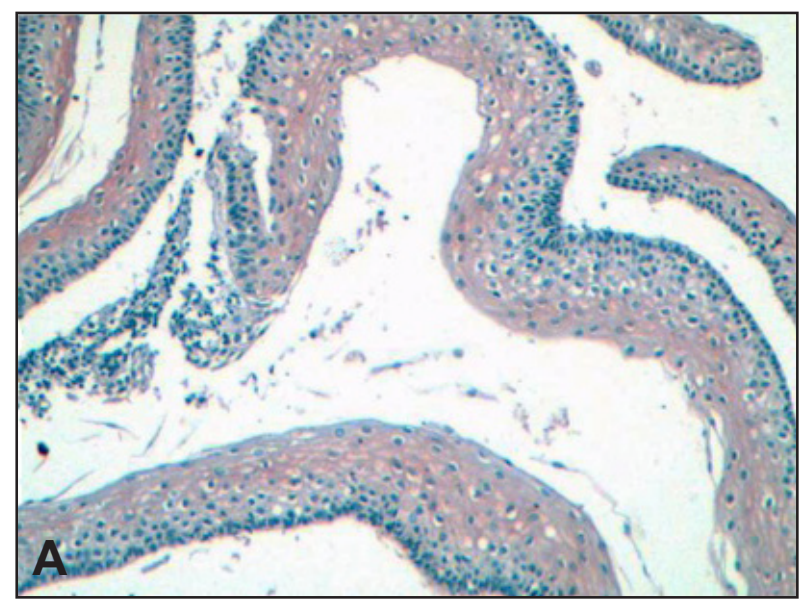

\section{Statistical analysis}

Chi-square test was used to statistical evaluate the results.

\section{RESULTS}

In all specimens analyzed and for both antigens, immunopositivity was relatively homogenous among cells and varied only in terms of intensity. As shown in Table 1, BiP/GRP78 immunopositivity was detected in 18 out of 24 (75\%) KCOTs. Positivity was marginal $(+/-)$ in one sample, mild $(+)$ in 10 , moderate $(++)$ in 6 and very intense $(+++)$ in one specimen. With the exception of 3 specimens exhibiting moderate or very intense immunopositivity and at which BiP/GRP78 expression was primarily localized in the upper layers of the epithelium (Figure 1A), in all other cases BiP/GRP78 immunopositivity spanned full thickness of the epithelium (Figure 1B). As opposed to KCOTs, PACs exhibited $\mathrm{BiP} /$ GRP78 immunopositivity in only 1 out of $9(13 \%)$ cases (Figure 2A) while all five FBs were negative for $\mathrm{BiP} / \mathrm{GRP} 78$ expression (Figure 2B) suggesting that the overexpression of BiP/GRP78 in KCOTs was statistically significant $\left(\mathrm{P}<0.001, \mathrm{x}^{2}\right.$-test $)$.

The same panel of specimens was also analyzed for the expression of calnexin. Our results that are summarized in Table 1 show that calnexin expression is significantly higher $(\mathrm{P}<0.001$, $\mathrm{x}^{2}$-test) in KCOTs since it was expressed in 11 out of 24 KCOTs $(46 \%)$ but only one out of $9(13 \%)$ PACs and none of the $5 \mathrm{FBs}$ analyzed. Immunopositivity in KCOTs ranged from marginal $(+/-)$ in 5 , mild $(+)$ in 5 and moderate $(++)$ in one specimen while the single PAC that was positive for calnexin expression exhibited marginal immunopositivity.



Figure 1. Immunohistochemical expression of BiP/GRP78 in keratocystic odontogenic tumours (x10). (A) Brown colour (DAB) indicates staining in the upper layers of the epithelium or $(B)$ in the full thickness with stronger intensity in the upper layers. Weak counterstaining with haematoxylin was performed in all samples following immunostaining (original magnification x20). 



Figure 2. The microphotograph shows negative staining for BiP/GRP78 in the epithelium of periapical cyst (A) and negative staining for calnexin in the epithelium of a fibroma (B). Weak counterstaining with haematoxylin was performed in all samples following immunostaining (original magnification x20).

Table 1. Expression levels and localization of BiP/GRP78 and calnexin in KCOTs, PACs and FBs

\begin{tabular}{|c|c|c|c|c|c|}
\hline $\begin{array}{l}\text { Specimen } \\
\text { No. }\end{array}$ & Age & $\begin{array}{c}\text { BiP/GRP78 expression } \\
\text { intensity }\end{array}$ & $\begin{array}{c}\text { BiP/GRP78 expression } \\
\text { localization }\end{array}$ & $\begin{array}{c}\text { Calnexin expression } \\
\text { intensity }\end{array}$ & $\begin{array}{c}\begin{array}{c}\text { Calnexin expression } \\
\text { localization }\end{array} \\
\end{array}$ \\
\hline \multicolumn{6}{|l|}{ KCOTs } \\
\hline 1 & 47 & - & & + & FT \\
\hline 2 & 74 & + & FT & \pm & FT \\
\hline 3 & 58 & + & FT & \pm & FT \\
\hline 4 & 40 & - & & - & \\
\hline 5 & 65 & ++ & UL & - & \\
\hline 6 & 62 & - & & - & \\
\hline 7 & 60 & - & & - & \\
\hline 8 & 43 & ++ & FT/UL & + & $\overline{\mathrm{UL}}$ \\
\hline 9 & 24 & +++ & UL & + & UL \\
\hline 10 & 33 & ++ & FT/UL & + & UL \\
\hline 11 & 51 & ++ & FT/UL & ++ & FT/UL \\
\hline 12 & 70 & - & & - & \\
\hline 13 & 66 & - & & - & \\
\hline 14 & 44 & + & FT & - & \\
\hline 15 & 40 & \pm & FT & \pm & FT \\
\hline 16 & 46 & + & FT & - & \\
\hline 17 & 47 & + & FT & + & FT \\
\hline 18 & 8 & ++ & FT/UL & + & FT \\
\hline 19 & 28 & ++ & FT & ++ & FT \\
\hline 20 & 57 & + & FT & \pm & FT \\
\hline 21 & 48 & + & FT & - & \\
\hline 22 & 45 & + & UL & - & \\
\hline 23 & 75 & + & FT/UL & - & \\
\hline 24 & 32 & + & FT & - & \\
\hline \multicolumn{6}{|l|}{ PACs } \\
\hline 1 & 57 & + & FT & \pm & FT \\
\hline 2 & 45 & - & & - & \\
\hline 3 & 32 & - & & - & \\
\hline 4 & 30 & - & & - & \\
\hline 5 & 53 & - & & - & \\
\hline 6 & 40 & - & & - & \\
\hline 7 & 52 & - & & - & \\
\hline 8 & 40 & - & & - & \\
\hline 9 & 45 & - & & - & \\
\hline \multicolumn{6}{|l|}{ FBs } \\
\hline 1 & 10 & - & & - & \\
\hline 2 & 56 & - & & - & \\
\hline 3 & 67 & - & & - & \\
\hline 4 & 50 & - & & - & \\
\hline 5 & 34 & - & & - & \\
\hline
\end{tabular}

KCOTs = keratocystic odontogenic tumors; PACs = periapical or radicular cysts; FBs = fibromas; FT = full thickness of the epithelium; $\mathrm{UL}=$ upper layers; FT/UL = full thickness with stronger intensity in the upper layers. 

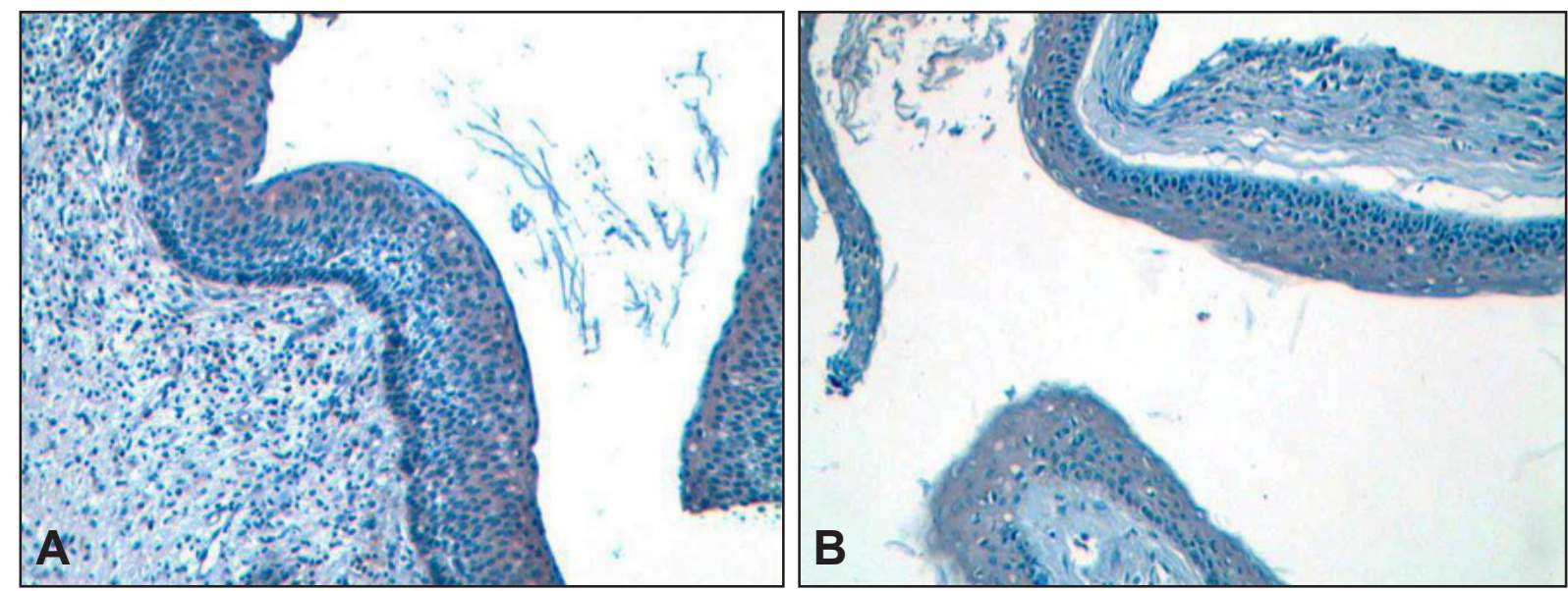

Figure 3. Immunohistochemical expression of calnexin in keratocystic odontogenic tumours (x10). (A) Brown colour (DAB) indicates staining in the upper layers of the epithelium or (B) in the full thickness. Weak counterstaining with haematoxylin was performed in all samples following immunostaining (original magnification $\mathrm{x} 20$ ).

In all but 3 cases that exhibited mild immunopositivity and was localized in the upper layers of the epithelium (Figure 3A), calnexin expression was spanned the full thickness of the epithelium (Figure 3B).

Considering that calnexin and BiP/GRP78 are both indicators of ER stress we asked if their expression is correlated in the same specimens. Indeed, out of the 38 specimens subjected to our analyses, 29 were either positive or negative for both antigens while only 9 exhibited expression for either BiP/GRP78 or calnexin. This observation confirms that BiP/GRP78 and calnexin are co-expressed $\left(\mathrm{P}<0.001, \mathrm{x}^{2}\right.$-test $)$.

\section{DISCUSSION}

In order to better understand the pathogenic mechanisms that underline the development of KCOTs we have hypothesized that ER stress and the resulting UPR may be associated with their onset. In order to test this hypothesis a bank of KCOTs specimens were analyzed by immunohistochemistry for the expression of BiP/GRP78 and calnexin, two widely used chaperones that are considered diagnostic for cells undergoing ER stress [19-21,23]. The expression of BiP/GRP78 and calnexin in the KCOTs were compared to that in PACs that are cysts with distinct pathologic features and pathogenetic mechanism from that of KCOTs as well as in FBs at which the cell type affected does not involve the epithelium but rather the stroma. Our results show a strong overexpression of the ER stress markers BiP/ GRP78 and calnexin in the KCOTs but not in the PACs and the FBs. Furthermore, these two chaperones were frequently co-expressed in the same specimens, an observation that implies that the overexpression of
BiP/GRP78 and calnexin was not coincidental but rather indicative for ER stress induction and execution of the UPR [23].

A distinct diagnostic feature of the KCOTs is the keratinization of the epithelium $[1, \underline{3}, 4]$. It is conceivable that this feature of the KCOTs, namely the misexpression of keratin, is causatively associated with ER stress. For reasons not yet well understood commitment to this keratinocyte differentiation program, may induce ER stress and activate the UPR $[24,25]$. Whether this is due to the ectopic overexpression of a specific protein such as keratin(s) or it is related to the perturbation of tissue homeostasis due to aberrant differentiation remains unclear. However, since neither PACs nor FBs display evidence of ER stress it is likely that the latter is linked to KCOTs' pathogenesis. Consistently with this notion, recent findings showed that in the skin, at which keratinization represents a normal and physiological process, ER stress-related chaperones BiP/GRP78 and HRD1 was elevated in cells of normal human epidermis that contain keratinocytes undergoing differentiation [24]. These findings suggest that keratinization, either in its physiological context such as in the skin or in abnormal context such as in the KCOTs, are associated with ER stress induction. Furthermore, in the same study it has been demonstrated that pharmacological interference with the execution of the UPR affected the differentiation of keratinocytes in vitro, providing further clues regarding the causative link between ER stress and keratinocyte differentiation [24]. Our results are consistent with these findings and suggest that ER stress is induced in the odontogenic epithelium when cells are committed to the keratinocyte differentiation program, during KCOT development. This is also supported by the observation that especially 
BiP/GRP78 and to some extent calnexin immunopositivity was frequently more intense in the upper layers of the epithelium at which keratinization is more prominent. Studies comparing the involvement of ER stress to parakeratinized normal tissues, hyperplastic and precancerous/dysplastic lesions of the oral epithelium would bestow insightful understanding if BiP/GRP78 or calnexin may be involved in parakeratinization. Indeed, a variety of diseases associated with aberrant keratinization, such as hereditary keratoses, including Darier's disease, keratosis linearis with ichthyosis congenita and keratoderma syndrome, erythrokeratoderma variabilis, and ichthyosis follicularis with atrichia and photophobia syndrome, have been linked to UPR [24]. It could be argued that keratinization and thus ER stress induction is irrelevant to the oncogenic stimulus that induces KCOTs' development. However, to the extent that keratinization reflects aberrant differentiation of the cells and considering that neoplastic development is indeed a disease of aberrant differentiation, ER stress is causatively linked to the disease development.

The results of the present study may provide clues regarding the pathogenesis of KCOTs. Which specific branches of UPR are activated during KCOT development and whether its inhibition is sufficient for the reversal of keratinization and regression of KCOTs remains to be explored. Furthermore, it would be of particular interest to investigate the involvement of epithelial to mesenchymal transitionassociated markers in the pathogenesis of KCOT and their potential link to ER stress. In view of recent findings linking mutations in PTCH1 gene to KCOTs' development, and considering that the PTCH1 gene's product is a secreted ligand, an interesting hypothesis would be that its expression induces ER stress $[26,27]$. This is also supported by the ability of PTCH1 to act on post ER SMO and to modulate its activity without affecting its overall expression levels [28].

These findings may have implications in the clinical practice at two major directions. The detection of ER stress and activation of the UPR may have diagnostic value for KCOT characterization especially in cases at which diagnosis is not clear especially in inflamed KCOTs [4] at which infiltration of the epithelium by inflammatory cells masks their typical histopathologic characteristics, raising issues of differential diagnosis. More importantly, considering that ER stress influences keratinocyte differentiation we may postulate that inhibition of UPR may have adjuvant therapeutic value for the management of KCOTs, particularly those with aggressive behaviour and often recurrences, at which surgery is the treatment of choice [29]. Indeed, recently developed chemical chaperones that can inhibit specific branches of the UPR may be beneficial for the therapy of KCOTs' patients.

\section{CONCLUSIONS}

This is the first demonstration of the involvement of endoplasmic reticulum stress in the pathogenesis of keratocystic odontogenic tumours. Understanding the precise mechanism by which endoplasmic reticulum stress is involved the development of keratocystic odontogenic tumours may find application in the diagnosis and management of the disease.

\section{ACKNOWLEDGMENTS AND DISCLOSURE STATEMENTS}

This study was supported by a Research Grant from the Empeirikion Foundation (granted to I.C.).

The authors declare that there are no conflicts of interest.

\section{REFERENCES}

1. Madras J, Lapointe H. Keratocystic odontogenic tumour: reclassification of the odontogenic keratocyst from cyst to tumour. J Can Dent Assoc. 2008 Mar;74(2):165-165h. [Medline: 18353202]

2. Sansare K, Raghav M, Mupparapu M, Mundada N, Karjodkar FR, Bansal S, Desai R. Keratocystic odontogenic tumor: systematic review with analysis of 72 additional cases from Mumbai, India. Oral Surg Oral Med Oral Pathol Oral Radiol. 2013 Jan;115(1):128-39. Review. Erratum in: Oral Surg Oral Med Oral Pathol Oral Radiol. 2013 Jun;115(6):841-2. [Medline: 23217544] [doi: 10.1016/j.000o.2012.10.005]

3. Barnes L, Eveson JW, Sidranski D, editors. World Organization Classification of Tumours. Pathology and Genetics of Head and Neck Tumours. IARC Press: Lyon; 2005.

4. Robinson RA, Vincent SD. Tumors and Cysts of the Jaws. AFIP Atlas of Tumor Pathology. 4th ser. Silver Spring, MD: American Registry of Pathology; 2012;64-68.

5. Ahlfors E, Larsson A, Sjögren S. The odontogenic keratocyst: a benign cystic tumor? J Oral Maxillofac Surg. 1984 Jan;42(1):10-9. [Medline: 6199488] [doi: 10.1016/0278-2391(84)90390-2] 
6. Agaram NP, Collins BM, Barnes L, Lomago D, Aldeeb D, Swalsky P, Finkelstein S, Hunt JL. Molecular analysis to demonstrate that odontogenic keratocysts are neoplastic. Arch Pathol Lab Med. 2004 Mar;128(3):313-7. [Medline: 14987156$]$

7. Johnson NR, Gannon OM, Savage NW, Batstone MD. Frequency of odontogenic cysts and tumors: a systematic review. J Investig Clin Dent. 2014 Feb;5(1):9-14. Epub 2013 Jun 14. [Medline: 23766099] [doi: 10.1111/jicd.12044]

8. Ponti G, Tomasi A, Pastorino L, Ruini C, Guarneri C, Mandel VD, Seidenari S, Pellacani G. Diagnostic and pathogenetic role of café-au-lait macules in nevoid basal cell carcinoma syndrome. Hered Cancer Clin Pract. 2012 Oct 29;10(1):15. doi: 10.1186/1897-4287-10-15. [Medline: 23107377] [PMC free article: 3502463] [doi: $10.1186 / 1897-4287-10-15]$

9. Gupta SR, Jaetli V, Mohanty S, Sharma R, Gupta A. Nevoid basal cell carcinoma syndrome in Indian patients: a clinical and radiological study of 6 cases and review of literature. Oral Surg Oral Med Oral Pathol Oral Radiol. 2012 Jan;113(1):99-110. doi: 10.1016/j.tripleo.2011.08.017. Epub 2012 Feb 3. Review. [Medline: 22669069] [doi: 10.1016/j.tripleo.2011.08.017]

10. Yoshida H. ER stress and diseases. FEBS J. 2007 Feb;274(3):630-58. Review. [Medline: 17288551] [doi: 10.1111/j.1742-4658.2007.05639.x]

11. Zhao L, Ackerman SL. Endoplasmic reticulum stress in health and disease. Curr Opin Cell Biol. 2006 Aug;18(4):44452. Epub 2006 Jun 16. Review. [Medline: 16781856] [doi: 10.1016/j.ceb.2006.06.005]

12. Lee AS, Hendershot LM. ER stress and cancer. Cancer Biol Ther. 2006 Jul;5(7):721-2. Epub 2006 Jul 1. Review. [Medline: 16880733] [doi: 10.4161/cbt.5.7.3120]

13. Harding HP, Ron D. Endoplasmic reticulum stress and the development of diabetes: a review. Diabetes. 2002 Dec;51 Suppl 3:S455-61. Review. [Medline: 12475790] [doi: 10.2337/diabetes.51.2007.S455]

14. Domon H, Takahashi N, Honda T, Nakajima T, Tabeta K, Abiko Y, Yamazaki K. Up-regulation of the endoplasmic reticulum stress-response in periodontal disease. Clin Chim Acta. 2009 Mar;401(1-2):134-40. Epub 2008 Dec 13. [Medline: 19109937] [doi: 10.1016/j.cca.2008.12.007]

15. Jorgensen E, Stinson A, Shan L, Yang J, Gietl D, Albino AP. Cigarette smoke induces endoplasmic reticulum stress and the unfolded protein response in normal and malignant human lung cells. BMC Cancer. 2008 Aug 11;8:229. [Medline: 18694499] [PMC free article: 2527015] [doi: 10.1186/1471-2407-8-229]

16. Yamaguchi Y, Larkin D, Lara-Lemus R, Ramos-Castañeda J, Liu M, Arvan P. Endoplasmic reticulum (ER) chaperone regulation and survival of cells compensating for deficiency in the ER stress response kinase, PERK. J Biol Chem. 2008 Jun 20;283(25):17020-9. Epub 2008 Apr 21. [Medline: 18426796] [PMC free article: 2427336] [doi: $10.1074 / \mathrm{jbc} . \mathrm{M} 802466200$ ]

17. Shen J, Snapp EL, Lippincott-Schwartz J, Prywes R. Stable binding of ATF6 to BiP in the endoplasmic reticulum stress response. Mol Cell Biol. 2005 Feb;25(3):921-32. [Medline: 15657421] [PMC free article: 543992] [doi: 10.1128/MCB.25.3.921-932.2005]

18. Zheng HC, Takahashi H, Li XH, Hara T, Masuda S, Guan YF, Takano Y. Overexpression of GRP78 and GRP94 are markers for aggressive behavior and poor prognosis in gastric carcinomas. Hum Pathol. 2008 Jul;39(7):1042-9. [Medline: 18482745] [doi: 10.1016/j.humpath.2007.11.009]

19. Lee AS. The ER chaperone and signaling regulator GRP78/BiP as a monitor of endoplasmic reticulum stress. Methods. 2005 Apr;35(4):373-81. [Medline: 15804610] [doi: 10.1016/j.ymeth.2004.10.010]

20. Pfaffenbach KT, Lee AS. The critical role of GRP78 in physiologic and pathologic stress. Curr Opin Cell Biol. 2011 Apr;23(2):150-6. Epub 2010 Oct 21. [Medline: 20970977] [PMC free article: 3043145] [doi: $10.1016 /$ j.ceb.2010.09.007]

21. Chevet E, Smirle J, Cameron PH, Thomas DY, Bergeron JJ. Calnexin phosphorylation: linking cytoplasmic signalling to endoplasmic reticulum lumenal functions. Semin Cell Dev Biol. 2010 Jul;21(5):486-90. Epub 2010 Jan 6. Review. [Medline: 20005969] [doi: 10.1016/j.semcdb.2009.12.005]

22. Wang WA, Groenendyk J, Michalak M. Calreticulin signaling in health and disease. Int J Biochem Cell Biol. 2012 Jun;44(6):842-6. Epub 2012 Feb 21. Review. [Medline: 22373697] [doi: 10.1016/j.biocel.2012.02.009]

23. Gupta D, Tuteja N. Chaperones and foldases in endoplasmic reticulum stress signaling in plants. Plant Signal Behav. 2011 Feb;6(2):232-6. Epub 2011 Feb 1. Review. [Medline: 21427533] [PMC free article: 3121983] [doi: $10.4161 /$ psb.6.2.15490]

24. Sugiura K. Unfolded protein response in keratinocytes: impact on normal and abnormal keratinization. J Dermatol Sci. 2013 Mar;69(3):181-6. Epub 2013 Jan 4. Review. [Medline: 23352280] [doi: 10.1016/j.jdermsci.2012.12.002]

25. Suzuki M, Endo M, Shinohara F, Echigo S, Rikiishi H. Enhancement of cisplatin cytotoxicity by SAHA involves endoplasmic reticulum stress-mediated apoptosis in oral squamous cell carcinoma cells. Cancer Chemother Pharmacol. 2009 Nov;64(6):1115-22. Epub 2009 Mar 11. [Medline: 19280190] [doi: 10.1007/s00280-009-0969-x]

26. Mendes RA, Carvalho JF, van der Waal I. Characterization and management of the keratocystic odontogenic tumor in relation to its histopathological and biological features. Oral Oncol. 2010 Apr;46(4):219-25. Epub 2010 Feb 26. Review. [Medline: 20189443] [doi: 10.1016/j.oraloncology.2010.01.012] 
27. Guo YY, Zhang JY, Li XF, Luo HY, Chen F, Li TJ. PTCH1 gene mutations in Keratocystic odontogenic tumors: a study of 43 Chinese patients and a systematic review. PLoS One. 2013 Oct 21;8(10):e77305. eCollection 2013. [Medline: 24204797] [PMC free article: 3804548] [doi: 10.1371/journal.pone.0077305]

28. Chen JK, Taipale J, Cooper MK, Beachy PA. Inhibition of Hedgehog signaling by direct binding of cyclopamine to Smoothened. Genes Dev. 2002 Nov 1;16(21):2743-8. [Medline: 12414725] [PMC free article: 187469] [doi: $10.1101 / \mathrm{gad} .1025302$ ]

29. Yildirim G, Ataoglu H, Kalayci A, Ozkan BT, Kucuk K, Esen A. Conservative Treatment Protocol for Keratocystic Odontogenic Tumour: a Follow-up Study of 3 Cases. J Oral Maxillofac Res. 2010 Oct 1;1(3):e7. eCollection 2010. [Medline: 24421977] [PMC free article: 3886057] [doi: 10.5037/jomr.2010.1307]

\section{To cite this article:}

Pavli M, Farmaki E, Merkourea S, Vastardis H, Sklavounou A, Tzerbos F, Chatzistamou I. Endoplasmic Reticulum StressAssociated Chaperones, Bip/GRP78 and Calnexin are Overexpressed in Keratocystic Odontogenic Tumours.

J Oral Maxillofac Res 2014;5(1):e3

URL: http://www.ejomr.org/JOMR/archives/2014/1/e3/v5n1e3ht.pdf

doi: $10.5037 /$ jomr.2014.5103

Copyright (C) Pavli M, Farmaki E, Merkourea S, Vastardis H, Sklavounou A, Tzerbos F, Chatzistamou I. Published in the JOURNAL OF ORAL \& MAXILLOFACIAL RESEARCH (http://www.ejomr.org), 1 April 2014.

This is an open-access article, first published in the JOURNAL OF ORAL \& MAXILLOFACIAL RESEARCH, distributed under the terms of the Creative Commons Attribution-Noncommercial-No Derivative Works 3.0 Unported License, which permits unrestricted non-commercial use, distribution, and reproduction in any medium, provided the original work and is properly cited. The copyright, license information and link to the original publication on (http://www.ejomr.org) must be included. 